\title{
Factors associated with hernia and bulge formation at the donor site of the pedicled TRAM flap
}

\author{
Luis Antonio Rossetto Luiz Eduardo Felipe Abla - Ronaldo Vidal • \\ Elvio Bueno Garcia • Ricardo João Gonzalez • Luiz Henrique Gebrim • \\ Miguel Sabino Neto $\cdot$ Lydia Masako Ferreira
}

Received: 18 August 2009 / Accepted: 2 March 2010/Published online: 7 April 2010

(C) The Author(s) 2010. This article is published with open access at Springerlink.com

\begin{abstract}
The purpose of this study was to evaluate the correlation between risk factors and hernia or bulge formation at the donor site of the transverse rectus abdominis myocutaneous (TRAM) flap. A retrospective study was conducted between September 2005 and December 2008 in 206 patients who underwent breast reconstruction with pedicled TRAM flap. Eight (3.9\%) of these patients had abdominal wall hernia and $26(12.6 \%)$ had abdominal bulging. The incidence of hernia was significantly higher $(P<0.05)$ among patients with body mass index $(\mathrm{BMI}) \geq$ $30 \mathrm{~kg} / \mathrm{m}^{2}$ (hernia incidence, $15.0 \%$ ) than that among patients with $\mathrm{BMI}<30 \mathrm{~kg} / \mathrm{m}^{2}$ (hernia incidence, $3.2 \%$ ), while the incidence of abdominal bulge was significantly lower $(P<0.05)$ among patients with $\mathrm{BMI} \geq 30 \mathrm{~kg} / \mathrm{m}^{2}$ (abdominal bulge incidence, 5.0\%) than that among patients with $\mathrm{BMI} \geq 30 \mathrm{~kg} / \mathrm{m}^{2}$ (abdominal bulge incidence, $19.1 \%$ ). Therefore, obesity was identified as a risk factor
\end{abstract}

L. A. Rossetto $\cdot$ R. Vidal

Graduate Program in Plastic Surgery, Federal University of São

Paulo School of Medicine (UNIFESP-EPM),

São Paulo, Brazil

\section{E. F. Abla $\cdot$ L. H. Gebrim}

Women's Health Reference Center, Pérola Byington Hospital, São Paulo, Brazil

\section{H. Gebrim}

Division of Senology, Department of Gynecology,

Federal University of São Paulo (UNIFESP),

São Paulo, Brazil

L. A. Rossetto $(\bowtie) \cdot$ L. E. F. Abla • E. B. Garcia •

R. J. Gonzalez $\cdot$ M. S. Neto $\cdot$ L. M. Ferreira

Division of Plastic Surgery, UNIFESP/EPM,

Rua Napoleão de Barros, 715-4 andar,

CEP 04024-002 São Paulo, SP, Brazil

e-mail: larossetto@uol.com.br for abdominal wall hernia. It was also found that the use of mesh to reinforce the abdominal wall significantly reduced $(P<0.025)$ the incidence of hernia (use of mesh (hernia incidence, $2.5 \%$ ) versus non-mesh (hernia incidence, $5.9 \%$ ) ) and abdominal bulge (use of mesh (abdominal bulge incidence, 9.9\%) versus non-mesh (abdominal bulge incidence, 17.3\%)) among the patients.

Keywords Surgical flaps · Mastectomy · Mammaplasty · Rectus abdominis $\cdot$ Breast diseases

\section{Introduction}

The transverse rectus abdominis myocutaneous (TRAM) flap was first described by Holmström [1] and popularized by Hartrampf et al. [2] and Gandolfo [3]. The TRAM flap allows breast reconstruction with analogous tissue, providing a natural appearance and consistency, and long-lasting results [4-7].

There are many different techniques for creating flaps, such as deep inferior epigastric perforator flaps and unipedicled [2,3], bipedicled [8], and microsurgical [1] TRAM flaps. However, these techniques create defects of various levels of severity in the abdominal wall, with abdominal hernia and bulge being the most common late complications $[4,9]$.

Reconstruction of the abdominal wall at the TRAM flap donor site is a great challenge, and there is no consensus on which is the best technique for flap elevation or closure of the abdominal wall $[9,10]$.

There are many relevant techniques for closure of the anterior abdominal wall, such as preservation of the rectus abdominis muscle and anterior rectus sheath [4, 11], and replacement of removed structures with either synthetic 
meshes [12-14] or autologous grafts [9, 15] and flaps [16-18], attempting to reduce morbidity at the donor site after TRAM flap elevation.

In the present study, the correlation between risk factors and hernia or bulge formation at the TRAM flap donor site was evaluated.

\section{Methods}

The present study was approved by the Research Ethics Committee at the Women's Health Reference Center, Pérola Byington Hospital, São Paulo, Brazil and was performed in accordance with the ethical standards laid down in the 1964 Declaration of Helsinki. Written informed consent was obtained from all patients. The patient's anonymity was carefully protected.

A retrospective study was conducted in 206 patients who underwent immediate or delayed breast reconstruction with pedicled TRAM flap at the Women's Health Reference Center, Pérola Byington Hospital, São Paulo, Brazil between September 2005 and December 2008. Clinical records were reviewed, and the incidence of abdominal hernia or bulge was evaluated.

The patients were clinically examined for the presence of abdominal bulge or hernia at the 6,12 , and 18 month follow-ups. Ultrasound was used to confirm the presence of abdominal bulge and/or hernia diagnosed by palpation or in the case of clinical suspicion.

A hernia was defined as dehiscence of the fascial closure and an abdominal bulge was defined as any asymmetrical abdominal bulging developed after the procedure $[19,20]$.

The following risk factors for hernia or bulge were evaluated: obesity (defined as body mass index (BMI) $\geq$ $30 \mathrm{~kg} / \mathrm{m}^{2}$ ); presence of comorbidities (systemic arterial hypertension, $\mathrm{SAH}$; diabetes mellitus, $\mathrm{DM}$; and chronic obstructive pulmonary disease, COPD) and smoking. Also, the following relevant factors, which may affect morbidity at the TRAM flap donor site were analyzed: presence of vertical median or paramedian abdominal scars, number of pedicles, and the use of mesh to reinforce the abdominal wall.

Eligibility criteria included women aged 20 and 65 years who underwent mastectomy. Exclusion criteria included patients who underwent previous abdominoplasty, who did not have excess tissue in the lower abdomen, and who had substantial weight loss.

\section{Patients}

From a total of 206 patients, 49 (23.8\%) had comorbidities (SAH, DM, and COPD), 48 (23.3\%) were smokers, and 13
(6.3\%) had vertical median or paramedian abdominal scars (Table 1).

In $58(28.2 \%)$ of the cases, a unipedicled TRAM flap was created, while a bipedicled TRAM flap was created in $148(71.8 \%)$ of the cases. A Marlex mesh was used for abdominal wall closure in $122(59.2 \%)$ of the patients of whom 19 (32.8\%) underwent unipedicled TRAM flap reconstruction and $103(69.6 \%)$ underwent bipedicled TRAM flap reconstruction.

Statistical analysis was performed using the Pearson chi-square test at a significance level of $P \leq 0.05$.

\section{Surgical procedures}

Elevation of the TRAM flap and abdominal flaps was performed with electrocautery. The TRAM flap was harvested using a muscle-sparing technique. After insetting the flap, abdominal closure was carried out. In the cases where the edges of the aponeurosis could be approximated without tension, primary fascial plication was performed with 2-0 monofilament nylon suture in a figure-of-eight fashion and reinforced with a running, double-stranded 2-0 monofilament nylon suture. However, when the edges of the aponeurosis could not be approximated without tension, a polypropylene mesh was used for the repair of the aponeurotic defect in the abdominal wall. The posterior face of the mesh was fixed with U-stitches (2-0 monofilament nylon), under the necessary tension, as a patch.

Table 1 Distribution of the number of patients according to age, comorbidities, and risk factors

\begin{tabular}{lc}
\hline Factors & $n(\%)$ \\
\hline Age & \\
Mean (range) & $45.6(29-64)$ years \\
Comorbidities & $39(18.9)$ \\
Systemic arterial hypertension $n(\%)$ & $6(2.9)$ \\
Diabetes mellitus $n(\%)$ & $2(1.0)$ \\
Chronic obstructive pulmonary & $2(1.0)$ \\
$\quad$ disease $n(\%)$ & \\
Others $n(\%)$ & \\
Risk factors & $25.9(18.7-34.8) \mathrm{kg} / \mathrm{m}^{2}$ \\
BMI (kg/m $\left.{ }^{2}\right)$ & $87(42.4)$ \\
Mean (range) & $80(38.7)$ \\
$<25 n(\%)$ & $39(18.9)$ \\
$25-30 n(\%)$ & $48(23.3)$ \\
$\geq 30 n(\%)$ & $13(6.3)$ \\
Smokers $n(\%)$ & \\
Vertical abdominal scars $n(\%)$ &
\end{tabular}

$B M I$ body mass index, $n$ number of patients 
When flaps were harvested bilaterally, a similar procedure was performed on the contralateral side.

In unipedicled TRAM flap patients, contralateral plication was performed in a similar manner in an attempt to centralize the umbilicus and correct the relative contour laxity of the contralateral abdomen. An abdominal flap was elevated for deep fixation of a second mesh to the periosteum of the three bony landmarks: the two anterosuperior iliac spines laterally, and the pubic symphysis inferiorly. The second polypropylene mesh $(20 \times 30 \mathrm{~cm})$ was placed over most of the abdominal wall and fixed under moderate tension with interrupted 2-0 monofilament nylon sutures at the three aforementioned bony sites. Two drains were left under the abdominal flap before the skin was closed in two layers.

\section{Results}

Hernia or bulge occurred in 34 of 206 patients; 11 (18.9\%) of these patients underwent unipedicled TRAM flap reconstruction and $23(15.5 \%)$ patients underwent bipedicled TRAM flap reconstruction.

Abdominal bulge was observed in 26 (12.6\%) patients; in ten $(17.2 \%)$ of the cases, a unipedicled TRAM flap was created, while a bipedicled TRAM flap was created in 16 $(10.8 \%)$ of the cases. Abdominal wall hernia was found in eight $(3.9 \%)$ patients; only one patient $(1.7 \%)$ had a unipedicled TRAM flap, while a bipedicled TRAM flap was created in seven $(4.7 \%)$ of the cases. There were no significant differences in the incidence of abdominal wall hernia or abdominal bulge between patients who underwent unipedicled TRAM flap reconstruction and those who underwent bipedicled TRAM flap reconstruction $(P=0.75)$.

The incidence rate of abdominal wall hernia was significantly higher $(P<0.05)$ among patients with $\mathrm{BMI} \geq$ $30 \mathrm{~kg} / \mathrm{m}^{2}$ (incidence of hernia, $15.0 \%$ ) than that among patients with $\mathrm{BMI}<30 \mathrm{~kg} / \mathrm{m}^{2}$ (incidence of hernia, $3.2 \%$ ). On the other hand, the incidence rate of abdominal bulge was significantly lower $(P<0.05)$ among patients with $\mathrm{BMI} \geq 30 \mathrm{~kg} / \mathrm{m}^{2}$ (incidence of abdominal bulge, $5.0 \%$ ) than that among patients with $\mathrm{BMI}<30 \mathrm{~kg} / \mathrm{m}^{2}$ (incidence of abdominal bulge, 19.1\%), as shown in Fig. 1 .

The characteristics of patients with $\mathrm{BMI} \geq 30 \mathrm{~kg} / \mathrm{m}^{2}$ were compared with those of patients with $\mathrm{BMI}<30 \mathrm{~kg} / \mathrm{m}^{2}$, and a significantly higher proportion $(P<0.05)$ of smokers was found among patients with $\mathrm{BMI}<30 \mathrm{~kg} / \mathrm{m}^{2}$ (Table 2). In the sample studied, there was a non-significant trend towards a higher incidence of abdominal hernia and bulge among non-smokers compared with that among smokers $(P=0.75)$.

The use of mesh in the reconstruction of the abdominal wall significantly reduced $(P<0.025)$ the incidence of abdominal wall hernia (use of mesh (incidence of hernia,

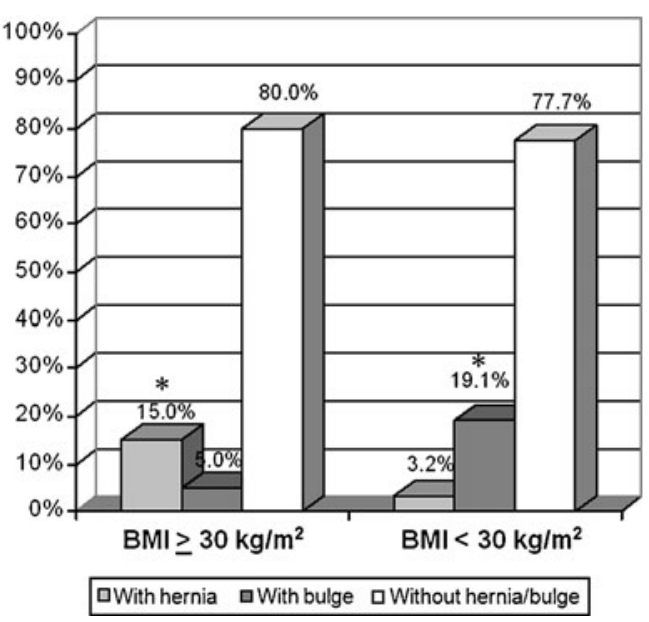

Fig. 1 Bar graph showing the relationship between the incidence (\%) of abdominal hernia or bulge and BMI values (kilogram per square meter). Asterisks indicate significantly higher incidence rates $(P \leq 0.05)$

$2.5 \%)$ versus non-mesh (incidence of hernia, 5.9\%)) and abdominal bulge (use of mesh (incidence of abdominal bulge, 9.9\%) versus non-mesh (incidence of abdominal bulge, 17.3\%)) among the patients (Fig. 2).

No significant differences in the incidence of abdominal hernia and bulge were found among patients with regard to the presence of comorbidities (SAH, DM, and COPD; $P=0.50)$, and presence of comorbidities combined with smoking $(P=0.95)$.

\section{Discussion}

The benefits of breast reconstruction after mastectomy are unquestionable. The TRAM flap for breast reconstruction is created only from autologous tissue (skin, adipose tissue, and muscle) of the abdomen, with no need for silicone implants. This technique allows a definitive reconstruction of the breast and provides excellent esthetic results with natural appearance and consistency. For these qualities, the

Table 2 Characteristics of patients according to body mass index (BMI, $\mathrm{kg} / \mathrm{m}^{2}$ )

\begin{tabular}{lccc}
\hline & $\begin{array}{l}\mathrm{BMI} \geq 30 \mathrm{~kg} / \mathrm{m}^{2} \\
n(\%)\end{array}$ & $\begin{array}{l}\mathrm{BMI}<30 \mathrm{~kg} / \mathrm{m}^{2} \\
n(\%)\end{array}$ & $P$ values \\
\hline Smokers & $1(5)$ & $25(26.6)$ & 0.05 \\
Use of mesh & $12(60)$ & $54(57.4)$ & 0.09 \\
Unipedicled TRAM flap & $8(40)$ & $21(22.3)$ & 0.25 \\
Bipedicled TRAM flap & $12(60)$ & $73(77.7)$ & 0.25 \\
Abdominal scar & $2(10)$ & $7(7.4)$ & 0.75 \\
Comorbidities & $7(35)$ & $22(23.4)$ & 0.25 \\
\hline
\end{tabular}

$n$ number of patients; Pearson chi-square test at a significance level of $P \leq 0.05$ 


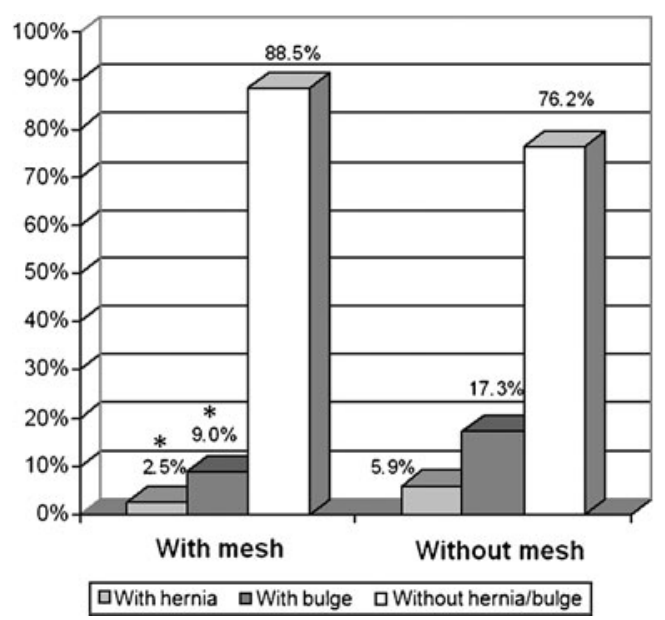

Fig. 2 Bar graph showing the relationship between the incidence (\%) of abdominal hernia or bulge and the use of mesh in abdominal wall reconstruction. Asterisks indicate significantly lower incidence rates $(P \leq 0.05)$

TRAM flap is considered by many authors the first option for breast reconstruction [5-7].

There are several strategies for preventing late abdominal wall complications at the TRAM flap donor site. These strategies may be divided into two major groups: preservation and replacement of structures.

The techniques for preservation of the structures at the TRAM flap donor site do not eliminate the risk of complications. Partial preservation of the rectus abdominis muscle and anterior rectus sheath does not prevent late muscle atrophy, which results in a weakened area [9]. Moreover, microsurgical techniques $[12,21]$ require welltrained surgeons and specific equipments; these are factors that increase the complexity and cost of the procedure, and make its use impractical in many nonspecialized centers.

In the present study, the incidence rate of abdominal wall hernia was $3.9 \%$, which is within the range of values reported in the literature $(0-10.53 \%)$ [8, 16, 22-24]. The incidence rate of abdominal bulge was $12.6 \%$, which also falls within the range described in literature (0-13.41\%) $[22,25,26]$.

The use of mesh for abdominal wall reinforcement in the closure of the TRAM flap donor site is associated with reduction in the rate of abdominal complications according to Banic et al. [5], and reduction in the incidence of abdominal hernia and bulge according to Kroll et al. [9] Zienowicz and May [15] and Moscona et al. [16] recommended the use of mesh to improve esthetic and functional aspects of the abdominal wall for patients who undergo TRAM flap reconstruction. On the other hand, Nahabedian and Manson [24] considered the use of mesh as a non-significant factor in the prevention of abnormal abdominal contour. In the present study, there was a significant reduction $(P<0.025)$ in the incidence of abdominal wall hernia and bulge among patients who had abdominal wall reconstruction with mesh.

Obesity was described as a risk factor for hernia formation by Chang et al. [19] and for abdominal wall hernia and bulge by Paige et al. [27]. According to Chang et al. [19], overweight is also a risk factor for abdominal hernia and bulge.

Our results showed an incidence of abdominal wall hernia significantly higher $(P<0.05)$ among patients with $\mathrm{BMI} \geq 30 \mathrm{~kg} / \mathrm{m}^{2}$ than among patients with $\mathrm{BMI}<30 \mathrm{~kg} / \mathrm{m}^{2}$, and an incidence of abdominal bulge significantly lower $(P<0.05)$ among patients with $\mathrm{BMI} \geq 30 \mathrm{~kg} / \mathrm{m}^{2}$ than among patients with $\mathrm{BMI}<30 \mathrm{~kg} / \mathrm{m}^{2}$.

A comparative analysis between obese and non-obese patients revealed a significantly higher proportion $(P<0.05)$ of smokers among non-obese patients (Table 2). Smoking was considered as a risk factor for hernia formation by Chang et al. [20] and for hernia and bulge formation by Paige et al. [27], but Nahabedian and Manson [24] report it as a non-significant factor. The higher proportion of smokers found among non-obese patients suggested that smoking could represent a risk factor for abdominal hernia and bulge formation in this group. However, in the present study, no statistically significant differences were found in the incidence of abdominal hernia or bulge between smokers and non-smokers.

The number of pedicles used for TRAM flap reconstruction (unipedicled or bipedicled) was not considered as risk factor for hernia and bulge formation by Kroll et al. [9]. Our results revealed no significant differences in the incidence of these complications between unipedicled and bipedicled TRAM flap reconstructions.

Hypertension and diabetes were not considered as risk factors by Paige et al. [27] and, according to Nahabedian and Manson [24], diabetes is not a significant risk factor for abnormal abdominal contour. There was no correlation between the incidence of hernia or bulge and presence of comorbidities (hypertension and diabetes) in the present study.

A median subumbilical abdominal scar was considered as a significant factor for hernia and bulge formation by Nahabedian and Manson [24]. However, no statistical correlation between the incidence of hernia or bulge and the presence of a previous median or paramedian abdominal scar was found in this study.

Several authors favor the use of synthetic meshes, which can be applied in different forms, according to the surgeon's experience [15, 17]. Meshes offer excellent structural support $[13,21]$, resulting in lower incidence of abdominal hernia and bulge in the closure of the TRAM flap donor site $[28,29]$. However, meshes alone do not allow the dynamic reconstruction of the abdominal wall [29, 30].

Autologous tissue flaps are a good option for closure of the abdominal wall at the TRAM flap donor site. The proximity of the autologous tissue flap donor site to the 
recipient site facilitates the procedure, reducing operative time and morbidity.

Ramirez et al. [21] described the "Components separation technique" for abdominal wall reconstruction, which consists in the creation of a musculo-aponeurotic flap with advancement of the internal oblique muscle and posterior rectus sheath. This technique was developed for the repair of hernias and was used with few changes for the closure of the unipedicled TRAM flap donor site.

Spear and Walker [31] described the external oblique flap; the technique consisted of making oblique incisions on the external oblique aponeurosis. This technique reduces the tension on the suture line at the donor site of unipedicled and bipedicled flaps. However, it weakens the outer surface of the abdominal wall.

Kroll et al. [32] described the internal oblique muscle flap for the repair of abdominal bulges secondary to the closure of the donor site. The flap is created by a vertical incision in the sheath of the rectus abdominis muscle extending to the peritoneal cavity.

Amir et al. [33] described the anterior rectus abdominis sheath flap for the closure of the TRAM flap donor site. This is a rectangular flap created on the upper border of the anterior rectus sheath and rotated to repair the defect. Similar to the synthetic meshes, this flap does not allow the dynamic reconstruction of the abdominal wall.

The reconstruction of the abdominal wall should restore its functional and structural support, resulting in a stable and dynamic closure [34], with the use of resistant materials and viable structures that provide a tension-free suture line [35]. One of the major causes of late complications in the closure of the abdominal wall is excessive tension on the suture line, which may lead to ischemia, necrosis, and dehiscence [29]. Therefore, techniques that result in reduced tension on the suture line are associated with a reduced incidence of hernias.

There is no consensus in the literature about the best technique to prevent abdominal wall complications after TRAM flap reconstruction. Various techniques have been developed for this purpose, such as preservation of abdominal wall structures, replacement of tissues by grafts or synthetic meshes, autologous flaps, and flaps associated with synthetic meshes, with techniques involving the use of synthetic meshes being the most commonly used.

Further studies will be necessary to develop improved techniques of abdominal wall closure at the TRAM flap donor site.

\section{Conclusion}

Obesity was considered as a risk factor for hernia formation, and the use of mesh in abdominal wall reconstruction was associated with a reduced incidence of abdominal hernia and bulge.

Disclosure statement The authors have no financial interest in any of the products, devices, or drugs mentioned in this manuscript.

\section{Conflict of interest None.}

Open Access This article is distributed under the terms of the Creative Commons Attribution Noncommercial License which permits any noncommercial use, distribution, and reproduction in any medium, provided the original author(s) and source are credited.

\section{References}

1. Holmström H (1979) The free abdominoplasty flap and its use in breast reconstruction: an experimental study and clinical case report. Scand J Plast Reconstr Surg 13:423-427

2. Hartrampf CR Jr, Scheflan M, Black P (1982) Breast reconstruction with a transverse abdominal island flap. Plast Reconstr Surg 69:216-225

3. Gandolfo EA (1982) Breast reconstruction with a lower abdominal myocutaneous flap. Br J Plast Surg 25:452-457

4. Edsander-Nord A, Jurell G, Wickman M (1998) Donor-site morbidity after pedicled or free TRAM flap surgery: a prospective and objective study. Plast Reconstr Surg 102:1508-1511

5. Banic A, Boeckx W, Greulich M, Marchi A, Rigotti G, Tschopp H (1995) Late results of breast reconstruction with free TRAM flaps: a prospective multicentric study. Plast Reconstr Surg 95(7):11951204

6. Veiga DF, Neto MS, Garcia EB et al (2002) Evaluations of the aesthetic results and patient satisfaction with the late pedicled TRAM flap breast reconstruction. Ann Plast Surg 48:515-520

7. Kokuba EM (2006) Health assessment questionnaire em pacientes submetidas à reconstrução mamária tardia com retalho musculocutâneo transverso do reto do abdome. Thesis, Universidade Federal de São Paulo

8. Ishii CH Jr, Bostwick J 3rd, Raine TJ, Coleman JJ 3rd, Hester TR (1985) Double-pedicle transverse rectus abdominis myocutaneous flap for unilateral breast and chest wall reconstruction. Plast Reconstr Surg 76:901-907

9. Kroll SS, Schusterman MA, Reece GP, Miler MJ, Geofrey R, Evans G (1995) Abdominal wall strength, bulging and hernia after TRAM flap breast reconstruction. Plast Reconstr Surg 96 (3):616-619

10. Rossetto LA, Garcia EB, Abla LF, Neto MS, Ferreira LM (2009) Quilting suture in the donor site of the transverse rectus abdominis musculocutaneous flap in breast reconstruction. Ann Plast Surg 62 (3):240-243

11. Kroll SS (1989) Midline fascial preservation in double-pedicle TRAM flap breast reconstruction. Ann Plast Surg 23:104-111

12. Noria K, Shintomi Y, Hosokawa M et al (1999) TRAM flap breast reconstruction using a fascia sparing technique. Nippon Geka Gakkai Zasshi 100:547-550

13. Hamdi M, Weiler-Mithoff EM, Webster MHC (1999) Deep inferior epigastric perforator flap in breast reconstruction: experience with the first 50 flaps. Plast Reconstr Surg 103:86-95 
14. Erni D, Harder YD (2003) The dissection of the rectus abdominis myocutaneous flap with complete preservation of the anterior rectus sheath. Br J Plast Surg 56(4):395-400

15. Zienowicz RJ, May JW (1995) Hernia prevention and aesthetic contouring of the abdomen following TRAM flap breast reconstruction by the use of polypropylene mesh. Plast Reconstr Surg 96(6):1346-1350

16. Moscona RA, Ramon Y, Toledano H, Barzilay G (1998) Use of synthetic mesh for the entire abdominal wall after TRAM flap transfer. Plast Reconstr Surg 101:706-710

17. Ascherman JA, Seruya M, Bartsich S (2008) Abdominal wall morbidity following unilateral and bilateral breast reconstruction with pedicled TRAM flaps: an outcomes analysis of 117 consecutive patients. Plast Reconstr Surg 121(1):1-8

18. Hein KD, Morris DJ, Goldwyn RM, Kolker A (1998) Dermal autografts for fascial repair after TRAM flap harvest. Plast Reconstr Surg 102:2287-2292

19. Chang DW, Wang B, Robb GL et al (2000) Effect of obesity on flap and donor site complications in free transverse rectus abdominis myocutaneous flap breast reconstruction. Plast Reconstr Surg 105(5):1640-1648

20. Chang DW, Reece GP, Wang B et al (2000) Effect of smoking on complications in patients undergoing free TRAM flap breast reconstruction. Plast Reconstr Surg 105(7):2374-2380

21. Ramirez OM, Ruas E, Dellon AL (1990) "Components separation" method for closure of abdominal wall defects: an anatomic and clinical study. Plast Reconstr Surg 86:519-526

22. Grotting JC, Urist MM, Maddox WA, Vasconez LO (1989) Conventional TRAM flap versus free microsurgical TRAM flap for immediate breast reconstruction. Plast Reconstr Surg 83 (5):828-841

23. Berrino P, Cambora E, Leone S et al (1991) The transverse rectus abdominis musculocutaneous flap for breast reconstruction in obese patients. Ann Plast Surg 27(3):221-231

24. Nahabedian MY, Manson PN (2002) Contour abnormalities of the abdomen after transverse rectus abdominis muscle flap breast reconstruction: a multifactorial analysis. Plast Reconstr Surg 109 (1):81-87
25. Rosen PB, Jabs AD, Kister SJ, Hugo NE (1990) Clinical experience with immediate breast reconstruction using tissue expansion or transverse rectus abdominis musculocutaneous flaps. Ann Plast Surg 25:249

26. Kroll SS, Netscher DT (1989) Complications of TRAM flap breast reconstruction in obese patients. Plast Reconstr Surg 84 (6):886-892

27. Paige KT, Bostwick J, Bried JT, Jones G (1998) A comparison of morbidity from bilateral, unipedicled and unilateral, unipedicled TRAM flap breast reconstructions. Plast Reconstr Surg 101 (7):1819-1820

28. Shestak KC, Fedele GM, Restifo RJ (2001) Treatment of difficult TRAM flap hernias using intraperitoneal synthetic mesh application. Plast Reconstr Surg 107:55-62

29. Nahas FX, Ferreira LM (2003) Cadaver as an experimental model to study abdominal wall tension. Acta Cir Bras 18(spe):37-45, Available from http://www.scielo.br/scielo.php?script=sci_arttext\& pid $=$ S0102-86502003001100006\&lng=en\&nrm=iso. Accessed 17 June 2009

30. Ennis LS, Young JS, Gamper TJ, Drake BD (2003) The "openbook" variation of component separation for repair of massive midline abdominal wall hernia. Am Surg 69:733-742

31. Spear SL, Walker RK (1992) The external oblique flap for reconstruction of the rectus sheath. Plast Reconstr Surg 90:608-613

32. Kroll SS, Schusterman MA, Mistry D (1995) The internal oblique repair of abdominal bulges secondary to TRAM flap breast reconstruction. Plast Reconstr Surg 96(1):100-104

33. Amir A, Siflen R, Hauben DJ (2003) Rotation flap of the anterior rectus abdominis sheath for hernia prevention in TRAM breast reconstruction. Ann Plast Surg 50:207

34. Rohrich RJ, Lowe JB, Hackney FL, Bowman JL, Hobar PC (2000) An algorithm for abdominal wall reconstruction. Plast Reconstr Surg 105:202

35. Larson GM (2000) Ventral hernia repair by the laparoscopic approach. Surg Clin North Am 80:1329-1340

36. Taylor GL, Corlett R, Boyd JB (1983) The extended deep inferior epigastric flap: a clinical technique. Plast Reconstr Surg 72:751-764 